STUDI

FRANCESI

\section{Studi Francesi}

Rivista quadrimestrale fondata da Franco Simone

168 (LVI | III) | 2012

Varia

\title{
Modernité du «Miroir des limbes». Un autre Malraux, sous la direction d'Henri Godard et Jean-Louis Jeannelle
}

Monia Mezzetti

\section{(2) OpenEdition}

Journals

\section{Edizione digitale}

URL: http://journals.openedition.org/studifrancesi/3849

DOI: $10.4000 /$ studifrancesi.3849

ISSN: 2421-5856

\section{Editore}

Rosenberg \& Sellier

\section{Edizione cartacea}

Data di pubblicazione: 1 décembre 2012

Paginazione: 608

ISSN: 0039-2944

\section{Notizia bibliografica digitale}

Monia Mezzetti, «Modernité du «Miroir des limbes». Un autre Malraux, sous la direction d'Henri Godard et Jean-Louis Jeannelle», Studi Francesi [Online], 168 (LVI | III) | 2012, online dal 30 novembre 2015, consultato il 07 mars 2021. URL: http://journals.openedition.org/studifrancesi/3849 ; DOI: https:// doi.org/10.4000/studifrancesi.3849

Questo documento è stato generato automaticamente il 7 mars 2021.

\section{cc) (†) $\odot$}

Studi Francesi è distribuita con Licenza Creative Commons Attribuzione - Non commerciale - Non opere derivate 4.0 Internazionale. 


\title{
Modernité du «Miroir des limbes». Un autre Malraux, sous la direction d'Henri Godard et Jean-Louis Jeannelle
}

\author{
Monia Mezzetti
}

\section{NOTIZIA}

Modernité du «Miroir des limbes». Un autre Malraux, sous la direction d'Henri GODARD et Jean-Louis JEANNELLE, Paris, Classiques Garnier, 2011 («Études de littérature des Xx et XXI ${ }^{\mathrm{e}}$ siècles», 18), pp. 395.

1 Indubbiamente quella operata nel convegno che è stato alla base del volume si configura come un'autentica scoperta, piuttosto che una riscoperta, dell'ultimo Malraux. Della consapevolezza dei suoi artefici al riguardo è indicativo il titolo, che alla parola modernité affida il compito di attirare l'attenzione su un'opera certo lontana dai suoi romanzi a tesi, ma che deve la sua, appunto, modernità alla rottura programmatica tanto con il romanzo quanto con l'autobiografia, il genere cui complessivamente l'opera è più affine (uno dei volumi del Miroir si intitola Antimémoires, 1967); una rottura talmente radicale, questa, da approdare a una scrittura dallo statuto incerto, inclassificabile, oscillante tra écriture de soi, rifiuto della fiction, uso del dialogo alla ricerca di un effet de réel, riflessioni sull'arte-un "modèle d'écriture de soi radicalement anti-biographique» (p. 299). Il volume si propone come un invito alla lettura e allo studio di un'opera poco conosciuta tanto dai lettori quanto in ambito accademico. Tale situazione viene fotografata nei contributi della prima sezione che indagano le ragioni storiche, ovvero culturali e politiche del Dopoguerra, del disinteresse per l'intellettuale Malraux e, di conseguenza, per i suoi ultimi lavori, a maggior ragione per il Miroir des limbes (1967-75), che ai più apparve e ancora appare 
“difficile", perfino «hautain» (p.154). La seconda parte esplora il versante autobiografico ricorrendo, quando possibile e necessario, all'interrogazione diretta dei dattiloscritti di Malraux, con le correzioni, le glosse di suo pugno a mo' di promemoria per integrazioni o rettifiche (Joël LOEHR, pp. 131-149). La terza sezione (pp.153-252) prende in esame lo statuto dell'opera stessa, inevitabilmente «au carrefour des genres»; i contributi si soffermano così sugli apporti finzionali e fattuali (Claude PILLET), sulla scrittura memoriale (Catherine COQUIO), sulla riflessione sull'arte (Henri GODARD). Alla ricezione di Malraux in scrittori come Jorge SEMPRUN (morto nel giugno 2011), Régis DEBRAY, Alix de SAINT-ANDRÉ, autori per l'occasione ciascuno di un proprio saggio, è invece dedicata la quarta parte. Chiude il volume un'interessante lettura attraverso gli strumenti della critica genetica di Lazare, l'ultima sezione del Miroir, scritta dopo un periodo di ricovero in ospedale nel 1972; in questo testo Malraux, partendo dalla propria esperienza di vulnerabilità e provvisorietà, elabora il concetto di «je-sans-moi» e lo studio dei manoscritti, proposti nella loro trascrizione diplomatica (pp. 341-383), rivela come tale rappresentazione mentale sia frutto di un'elaborazione avvenuta principalmente attraverso la scrittura, contestualmente ad essa, il che fa modernamente della scrittura un luogo di scoperta. 